А.Р. Ожегова

Национальный исследовательский университет

«Высшая школа экономики», Пермь

\title{
E.M. Ожегов
}

Национальный исследовательский университет

«Высшая школа экономики», Пермь

\section{Оценка функции спроса на театральные постановки: эмпирический анализ}

Аннотация. Целью государственных театров является как увеличение выручки, так и увеличение числа зрителей. Достижение такого рода цели связано с изучением функции спроса на театральные билеты при непосредственном фокусе на оценку ценовой эластичности спроса. В предыдущих работах, изучавших спрос на театральные постановки, получены противоречивые оценки эластичности спроса. Оценки ценовой эластичности разнятся по странам, изучаемым театрам, отдельным сегментам зрителей, а также находятся в зависимости от уровня агрегирования данных. Агрегированные до уровня отдельных театров или стран данные о посещаемости театров и цен на билеты обычно не позволяют учитывать различия в качестве культурного продукта, производимого театрами. Некорректный учет или неучет качества театров, их отдельных постановок, а также мест в зале приводит к проблеме пропущенных переменных и смещению оценок ценовой эластичности спроса. В этой работе на дезагрегрированных данных о продаже билетов в Пермский театр оперы и балета за четыре театральных сезона выявляется әффект цены на спрос на билеты для различных типов спектаклей и мест в зале. С помощью метода цензурированной квантильной регрессии оцениваются параметры функции спроса. В работе выявлено, что спрос на театральные постановки Пермского театра оперы и балета является слабо эластичным по цене. Также в работе показано, что неучет качественных характеристик спектаклей и мест в зале, а также ограниченной вместимости зала приводит к смещению оценок функции спроса.

Ключевые слова: спрос, театр, экономика культуры, иеновая эластичность. Классификация JEL: Z11, D12, C24.

\section{Введение}

Рынок исполнительских искусств является предметом пристального изучения со стороны экономистов, социологов и маркетологов, поскольку данный рынок характеризуется разнородностью моделей поведения как продавцов, так и потребителей. На данный момент существует множество работ, посвященных исследованию театра, при этом часть из них изучает вопросы государственной поддержки театров, әффективного ценообразования и ценовой дискриминации на рынке театральных услуг. Другая область исследований посвящена изучению спроса посетителей театральных услуг. И та, и другая область тесно взаимодействуют между собой, поскольку принятие решений одними агентами зависит от поведения других. В данной работе мы сосредоточились на эконометрическом исследовании спроса на услуги музыкального театра, фокусируясь на вопросе корректной оценки эластичности спроса по цене. 
В научной литературе широко обсуждается тот факт, что экономика культуры подвержена так называемой «болезни цен» (Baumol, Bowen, 1966). Суть болезни состоит в том, что в отличие от других отраслей экономики в сфере исполнительских искусств рост производительности труда практически отсутствует. Вследствие низких темпов производительности доходы организаций могут расти только за счет роста цен. Что касается роста издержек, то оплата труда в сфере культуры растет вслед за ростом оплаты труда в экономике, увеличивая тем самым разрыв между доходами и расходами организаций (Рубинштейн, 2012). Вследствие возрастающей динамики дефицита доходов театр вынужден повышать цены на билеты, чтобы хотя бы частично покрывать издержки на спектакли. Важным замечанием является то, что цели театра отличаются от целей коммерческих организаций. Театр стремится приобщать население к культурным ценностям, развивать художественный вкус, поэтому услуги театра должны быть доступны для населения. При этом возникает вопрос, может ли театр повышать цены на билеты быстрее инфляции, не отпугнув при этом потребителя, т.е. не снижая показателей посещаемости, что и обосновывает актуальность изучения реакции зрительского спроса на изменение цен.

Настоящее исследование посвящено эконометрическому оцениванию функции спроса на постановки Пермского театра оперы и балета. Изучение ценовой эластичности спроса позволит, в конечном счете, выработать рекомендации для увеличения эффективности ценовой политики данного театра. При моделировании спроса на театральные услуги следует учитывать несколько групп факторов. В первую очередь спрос зависит от цены билетов. При этом обычно изучается влияние на спрос либо цен, установленных театром (базовых цен), либо фактических цен продажи билетов, т.е. цен с учетом скидок. Поскольку по итогу исследования мы планируем дать рекомендации руководству театра для повышения эффективности ценовой политики, то кажется целесообразным включить в функцию спроса цены, которыми театр может управлять, т.е. цены без учета персональных скидок посетителей. Вторая группа факторов, которая, как правило, объясняет большую долю изменений спроса, это характеристики художественного продукта, которые можно разделить на характеристики конкретного спектакля и характеристики конкретного показа спектакля. К характеристикам спектаклей обычно относят тип спектакля (опера, балет, мюзикл, драматическая постановка и др.), известность режиссера, дирижера, автора и постановки. Также используются различные классификации постановок: классические и современные, исполняющиеся на иностранном языке и на национальном языке и др. Характеристиками показа являются показатели времени: год, сезон, месяц, день недели и время дня. Помимо характеристик важно учитывать качество спектаклей. Здесь используются разные показа- 
тели, начиная от рейтингов спектаклей, заканчивая критическими обзорами. Также существует общепризнанная зависимость между текущим спросом на исполнительское искусство и интенсивностью прошлого потребления, а также восприятием прошлого потребления (Автономов, 2011). Еще одна группа факторов позволяет контролировать характеристики зрителей - социально-демографические показатели: пол, возраст, образование, профессия, доход, приобщенность к театральному искусству и др.

В целом спросу на театральные постановки присущи черты, отмечаемые исследователями спроса на другие зрелищные мероприятия: спортивные события, кинопоказы и др. В обзорной работе о спросе на спортивные мероприятия (Borland, MacDonald, 2003) отмечается, что продукт на данном рынке является комбинированным, он включает как характеристики самого зрелища (играющие команды, неопределенность результата), так и характеристики конкретного похода (время суток, день недели, месяц, качество стадиона и места). Также авторами отмечается, что число проданных билетов ограничено вместимостью стадиона, что также следует учитывать при формировании эконометрической модели спроса. Исследователи спроса на кинопоказы также отмечают, что он может существенно различаться по времени суток и дню недели показа, а также по времени года (Orbach, Einav, 2007) и по различным социальным группам (Kimes, Chase, 1998). Авторы (Kimes, Wirtz, 2003) отмечают различия в восприятии качества отдельных мест в зале кинотеатра, однако говорят также, что ценовая дифференциация по времени показа и местам в зале может быть слишком сложной для потребителя (Litman, 1998) либо восприниматься ими как «нечестная» (Choi, Jeong, Mattila, 2015).

Данные, предоставленные для исследования, содержат информацию о числе проданных билетов на каждый спектакль в плане ценовых поясов, на которые поделен зал театра, а также информацию о цене билета в каждом ценовом поясе. Дополнительно была собрана информация о характеристиках спектаклей и отдельных показов, а также показатели, отвечающие за качество постановок. При этом данные не содержат персональной информации о покупателе билета, что не позволяет учитывать вариации структуры аудитории во времени, а также информацию об истории потребления каждого посетителя, что не дает возможности оценить влияние прошлого потребления на текущее время.

Таким образом, имея информацию по трем группам факторов, мы можем сделать предположение о функциональной зависимости спроса. Мы ожидаем, что спрос отрицательно зависит от цены, что согласуется с опытом большинства предыдущих исследований, оценивающих спрос на культурные блага. При этом некоторые авторы (Jenkins, Austen-Smith, 1987) эмпирически доказали, что спрос может положительно зависеть от цены, что объясняется наличием в модели 
пропущенных переменных, отвечающих за качество постановки. Поэтому помимо цены в модели стоит учитывать характеристики спектаклей и показов, а также качество постановок, что должно объяснять существенную долю вариации спроса. Следует учитывать также, что зал разделен на несколько ценовых поясов, внутри которых установлена единая цена на билеты, при этом цена билетов разных поясов отличается. Тогда если цена является сигналом о качестве места (пояса), то неучет качества места приведет к заниженной оценке ценовой эластичности. Для того чтобы проверить это предположение, мы будем использовать структуру данных, дезагрегированную до уровня спроса на отдельный пояс некоторого спектакля, где в качестве зависимой переменной будет выступать заполняемость пояса на конкретный показ спектакля. Такая структура позволяет получить детальное представление о структуре спроса на разные места в театре и учесть различия в качестве мест в зрительном зале.

Среди авторов работ, посвященных идентификации функции спроса, нет единого мнения о том, эластичен ли спрос на театральные услуги по цене (Throsby, Withers, 1979; Withers, 1980; Greckel, Felton, 1987; Felton, 1989; Krebs, Pommerehne, 1995). Несмотря на то что много работ изучает этот вопрос, нет единого мнения по поводу того, как и от чего зависит спрос и будет ли он эластичным или неэластичным. Структура данных, а также обширный набор характеристик спектаклей и показов позволят нам проверить, приводит ли неучет качественных характеристик постановок и мест в зале к смещению оценки ценовой эластичности и неверной интерпретации результатов. Детальная структура данных поможет также ответить на вопрос, влияет ли уровень агрегирования данных на оценки функции спроса. Кроме того, в предыдущих работах неоднократно обсуждался вопрос об ограниченной вместимости зала театра, что было учтено лишь в некоторых недавних работах (Laamanen, 2013). В рамках данной работы мы также проверим, влияет ли ограниченная вместимость зала на оценки параметров функции спроса.

Структура изложения выстроена следующим образом. Разд. 1 посвящен обзору релевантной литературы. В разд. 2 представлено детальное описание данных с указанием структуры, которая используется при оценивании. В разд. 3 предлагается эконометрическая модель функции спроса на театральные постановки. Разд. 4 содержит результаты эконометрической оценки функции спроса. Наконец, в последнем разделе обобщаются основные выводы и обсуждаются ограничения модели.

\section{1. Обзор литературы}

Традиционно исследования спроса на исполнительское искусство используют два основных подхода: выявление предпочтений на основе данных по посещаемости и продажам (метод выявленных пред- 
почтений), использование данных опросных анкет (метод заявленных предпочтений). Работы, основанные на методе заявленных предпочтений, как правило, изучают зависимости спроса от социально-демографических характеристик публики (Colbert, Nantel, 1989; Baumol, Bowen, 1966; Levy-Garboua, Montmarquette, 1996; Schulze, Rose, 1998). Целью исследований, основанных на методе выявленных предпочтений, является оценка функции спроса на исполнительское искусство, а также оценка параметров эластичности спроса по цене, доходу, цене товаров-заменителей и сопутствующих товаров (Moore, 1966; Throsby, Withers, 1979; Schimmelpfennig, 1997; Levy-Garboua, Montmarquette, 1996; Zieba, 2009). Дальнейший анализ литературы посвящен эмпирическим исследованиям спроса на исполнительское искусство, опирающимся на фактические данные о продажах.

В литературе, посвященной экономике культуры, часто возникает обсуждение, подвержено ли исполнительское искусство эффекту Веблена. Об эффекте Веблена говорят, когда наблюдается положительная взаимная связь между спросом и ценой. Потребители покупают такой товар с целью продемонстрировать особый статус, позволяющий им приобретать товары, недоступные массовому потребителю. Работы, посвященные оценке ценовой эластичности спроса, показывают, что наличие положительной взаимосвязи, как правило, свидетельствует о пропущенных переменных в модели (Jenkins, Austen-Smith, 1987). Поскольку в функции спроса на спектакли отсутствует параметр, отвечающий за качество, то пропущенная переменная оказывает одновременное влияние и на цену, и на спрос. В этом случае цена будет являться сигналом качества, а высокий уровень цен на некоторые спектакли будет свидетельствовать о высоком качестве постановки.

Также до сих пор остается открытым вопрос о том, стоит ли относить исполнительское искусство к товарам роскоши. Поскольку предыдущие исследования неоднократно подчеркивали, что основная аудитория музыкальных театров в России - общественная элита с точки зрения образования и доходов, то исполнительское искусство следует считать товаром роскоши, а значит, спрос на него должен быть эластичным по цене. Анализ литературы, посвященной оценке спроса, дает противоречивые результаты. Результаты ранних исследований свидетельствуют о том, что спрос на театральные постановки неэластичен по цене (Moore, 1966; Houthakker, Taylor, 1970; Touchstone, 1980; Gapinski, 1984; Bonato, Gagliardi, Gorelli, 1990). В пользу неэластичности спроса могут свидетельствовать различные факторы. Во-первых, отсутствие близких заменителей может повлиять на эластичность. Так, изучая спрос на музыкальные театры, мы понимаем, что в большинстве городов, за исключением столиц, музыкальный театр там один. Тогда неэластичность спроса может быть объяснена отсутствием близких для потребителя альтернатив. Во-вторых, несо- 
вершенство информации или слабая осведомленность покупателей на рынке может приводить к не лучшим покупкам. Чем больше у потребителя времени на обдумывание, тем более эластичным будет его спрос. В случае с театром в начале сезона у потребителя есть выбор, пойти на спектакль в этом месяце или через несколько месяцев, тогда потребитель при прочих равных выберет спектакль с более низкой ценой. В исследовании (Krebs, Pommerehne, 1995) авторы показали, что эффект изменения цены может быть отложенным: в краткосрочном периоде спрос на театральные постановки слабо эластичен по цене, но он эластичен в долгосрочном плане. Кроме того, низкую эластичность спроса по цене можно объяснить тем, что цена на билет составляет лишь часть затрат посетителя на поход в театр. За исключением видимых затрат зритель на посещение театра тратит время, а значит, несет альтернативные издержки (Seaman, 2006). Тогда полная стоимость посещения театра чаще всего превышает цену билета, что частично объясняет нечувствительность спроса к изменению цен на билеты. Таким образом, причины неэластичности спроса могут быть связаны с особенностями рынка исполнительских искусств.

Другой причиной неэластичности или низких показателей эластичности может стать агрегированная структура данных. Вышеупомянутые исследования изучали спрос на агрегированных данных, в результате чего зачастую не получали эмпирических доказательств эластичности потребителей. Основной проблемой, возникающей в результате агрегирования, является потеря информации о разнородности. Как правило, спрос на билеты в разные секторы зала, спектакли с разными характеристиками предъявляют разные сегменты людей в терминах дохода, образования, профессии и художественного вкуса (Автономов, 2014). Для более тщательного изучения влияния цены и других характеристик на спрос необходимо использовать данные, детализированные по каким-либо ключевым признакам. В исследовании (Pommerehne, Kirchgassner, 1987) авторы выявили более низкие показатели эластичности для людей с более высоким уровнем дохода. Используя данные о посещаемости по ценовым поясам, автор работы (Schimmelpfennig, 1997) нашел различия в показателях эластичности для разных секторов зала. В исследовании (Throsby, 1994) виды искусства были классифицированы на «доступные» (immediately accessible arts) и «высокие» (higher arts). Спрос на «высокие» виды искусства оказался менее эластичным, что автор объяснил тем, что аудитория «высоких» видов искусств ориентируется больше на качество, чем на цену билета. Таким образом, оценка эластичности спроса на агрегированных данных чаще всего приводит к тому, что спрос неэластичен по цене. В то же время более детальные данные показывают, что спрос может быть эластичным для некоторых сегментов зрителей, для отдельных регионов, театров, спектаклей. 
Поскольку театральные постановки являются дифференцированным товаром, более поздние работы, основанные на детализированных по спектаклям данных, помимо цены включают в функцию спроса также характеристики постановок, среди которых стоит выделить тип спектакля, репертуарную классификацию, уровень выступления (Corning, Levy, 2002; Willis, Snowball, 2009).

Особое внимание уделяется фактору, отвечающему за качество постановки. Ранние работы в качестве меры качества постановки брали расходы театра на костюмы, декорации, гонорар режиссеру (Hansmann, 1981). Значительный вклад в понимание оценки качества постановки был сделан в работе (Throsby, 1990). Позже в качестве оценки качества спектаклей авторы предложили различные субъективные измерители: репутация театра (Urrutiaguer, 2002), репутация режиссера (Urrutiaguer, 2002; Willis, Snowball, 2009), уровень дизайна декораций и костюмов (Zieba, 2009), обзоры критиков (Corning, Levy, 2002) и др. В ходе многих исследований удалось выяснить, что огромная доля спроса объясняется качеством постановки и характеристиками спектакля.

Таким образом, многочисленные исследования были посвящены изучению ценовой эластичности спроса. Существуют разные теоретические гипотезы, свидетельствующие в пользу того, что спрос должен быть эластичен по цене, в защиту чего также можно привести различные особенности рынка исполнительских искусств, в частности характеристики публики. В это же время накопленный опыт предыдущих исследований говорит нам о том, что спрос может быть неэластичен по цене, что также может быть обусловлено качественными характеристиками постановок и демографическими характеристиками аудитории. Несмотря на множество эмпирических исследований, основанных на данных зарубежных культурных организаций, эконометрических исследований функции спроса на театральные постановки на данных российских театров до сих пор не осуществлялось. Исключение составляет исследование, посвященное эмпирической проверке теоретической закономерности - «болезни цен» (Рубинштейн, 2012). В данной работе автор разработал модель «болезни цен», а в качестве следствия оценил влияние сверхинфляционного роста цен на билеты на размер дефицита доходов учреждений культуры. Результаты этого исследования свидетельствуют о том, что рост цен на билеты сверх уровня инфляции приводит к увеличению дефицита доходов, а значит, приводит к снижению посещаемости учреждений исполнительских искусств, и в частности театров. Снижение посещаемости спектаклей в результате роста цен, в свою очередь, говорит о том, что потребители чувствительны к изменению цены. В данном исследовании оценивание производится на агрегированных данных о доходах российских театральных организаций. Однако такая структура данных не позволяет говорить о величине эла- 
стичности спроса, а только показывает зависимость между дефицитом доходов и реальным уровнем цен. Агрегированная структура данных по учреждениям культуры позволяет получить представление об экономике культурных организаций в России в целом, но не учитывает особенностей отдельных организаций и их аудитории.

Видится, что для корректной оценки функции спроса на театральные постановки следует в качестве детерминант спроса использовать цену на билеты, качественные характеристики спектаклей и постановок, а также использовать максимально дезагрегированную структуру данных. Излишняя степень агрегирования данных или пропуск качественных переменных может приводить к смещению оценок ценовой эластичности, а также некорректной интерпретации свойств произведений исполнительского искусства как товара.

\section{2. Описание данных}

Данные для исследования были предоставлены Пермским академическим театром оперы и балета имени П.И. Чайковского, одним из старейших музыкальных театров России. Исходные данные включают информацию о спектаклях за четыре прошедших сезона (2011/2012, 2012/2013, 2013/2014, 2014/2015). За это время театральной труппой было представлено 985 показов 170 постановок. За четыре сезона театр показывал постановки как на основной сцене театра, так и на других сценических площадках, к примеру, в фойе театра. В данное исследование попали спектакли, которые были показаны на основной сцене. Доля таких спектаклей составляет $70 \%$ общего числа спектаклей и приносит $94 \%$ всей выручки театра. Также в ходе анализа данных было выявлено четыре варианта разделения зрительного зала на ценовые пояса. Один из вариантов встречается в данных существенно чаще других, на него приходится $80 \%$ всех показов. Остальные варианты деления зала относятся скорее к нетипичным мероприятиям: детским спектаклям, творческим встречам и т.д. В данном исследовании мы ограничили выборку спектаклями, показанными в рамках одного основного варианта разделения зала на пояса, так как это позволяет, помимо прочего, однородно судить о качестве места по идентификатору ценового пояса. Помимо этого, мы ограничили выборку репертуарными постановками, т.е. операми и балетами, исключив однократные мероприятия: симфонические концерты и фестивальные мероприятия. Таким образом, из имеющихся 985 показов для оценивания параметров функции спроса мы оставили 298.

Данные, предоставленные театром, включают информацию о названии спектакля, дате показа (сезон, год, месяц, день недели и время дня), числе и расположении мест, на которые проданы билеты в зрительном зале. Зал театра делится на девять ценовых поясов в зависимости от удаленности от сцены и качества обзора. Схема деления зала на ценовые пояса в соответствии с основным вариантом деле- 
ния мест представлена на рис. 1. В данных есть информация о базовой цене билета (без учета персональной скидки), установленной театром на места в определенном поясе. На места одного пояса в рамках одного показа театром устанавливается одинаковая цена. Цена билета при этом варьирует как по постановкам, так и по показам одной постановки. Поскольку базовая цена билета в рамках одного ценового пояса и показа является одинаковой, мы предполагаем, что места, находящиеся в одном ценовом поясе, однородны по качеству. Качество мест, цена и потенциальная аудитория разных ценовых поясов является различной, таким образом, кажется оправданным сосредоточиться на оценке функции спроса на уровне ценового пояса, для чего данные по продажам билетов были агрегированы по поясам. Для каждого пояса мы рассчитали заполняемость как долю проданных билетов от общего числа мест в данном поясе. В качестве единицы наблюдения мы рассматриваем заполняемость конкретного пояса на конкретный показ спектакля (298 спектаклей $\times 9$ поясов $=2682$ наблюдения). В табл. 1 указаны описательные статистики базовой цены и уровня заполняемости в разрезе ценовых поясов.

Как было сказано ранее, спрос на театральные постановки в значительной степени зависит от характеристик постановки, поэ-

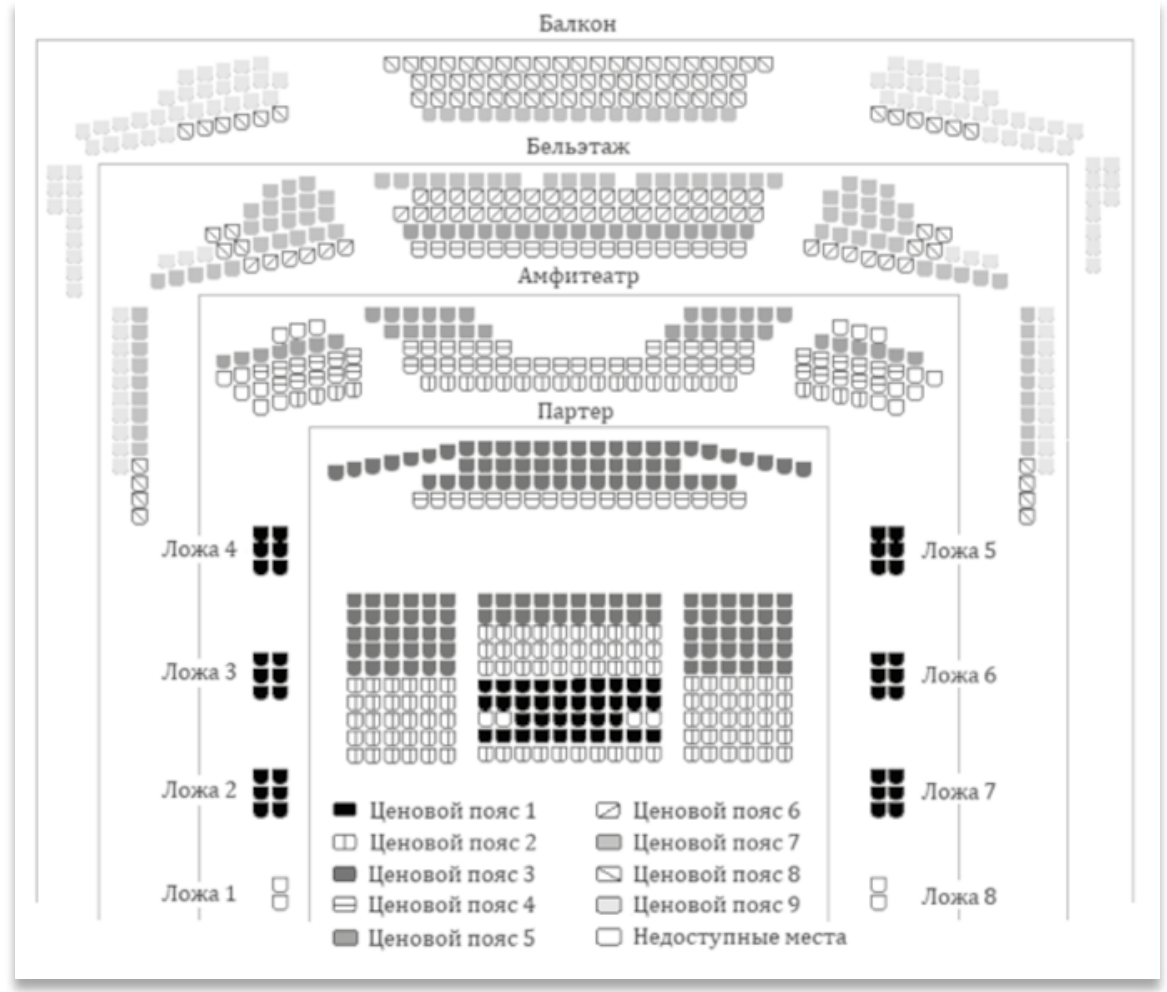

Рис. 1

Пример схемы деления зала на ченовые пояса 
Таблица 1

Описательные статистики цен и заполняемости

\begin{tabular}{|c|c|c|c|c|c|}
\hline Переменная & $\begin{array}{c}\text { Число } \\
\text { наблюдений }\end{array}$ & $\begin{array}{c}\text { Среднее } \\
\text { значение }\end{array}$ & $\begin{array}{c}\text { Стандартное } \\
\text { отклонение }\end{array}$ & $\begin{array}{c}\text { Минималь- } \\
\text { ное значение }\end{array}$ & $\begin{array}{c}\text { Максималь- } \\
\text { ное значение }\end{array}$ \\
\hline \multicolumn{6}{|c|}{ Характеристики цены } \\
\hline Базовая цена, руб. & 2682 & 387,1 & 366,9 & 100 & 2000 \\
\hline Пояс 1 & 298 & 868,1 & 496,6 & 300 & 2000 \\
\hline Пояс 2 & 298 & 578,4 & 380,2 & 250 & 1400 \\
\hline Пояс 3 & 298 & 486,5 & 351,6 & 210 & 1300 \\
\hline Пояс 4 & 298 & 427,7 & 323,5 & 180 & 1200 \\
\hline Пояс 5 & 298 & 349,6 & 265,8 & 160 & 1000 \\
\hline Пояс 6 & 298 & 277,5 & 211,3 & 140 & 800 \\
\hline Пояс 7 & 298 & 224,4 & 151,1 & 120 & 600 \\
\hline Пояс 8 & 298 & 171,4 & 89,9 & 110 & 400 \\
\hline Пояс 9 & 298 & 100 & 0 & 100 & 100 \\
\hline \multicolumn{6}{|c|}{ Характеристики заполняемости } \\
\hline Заполняемость, доля & 2682 & 0,80 & 0,26 & 0,01 & 1 \\
\hline Пояс 1 & 298 & 0,86 & 0,15 & 0,24 & 1 \\
\hline Пояс 2 & 298 & 0,90 & 0,13 & 0,35 & 1 \\
\hline Пояс 3 & 298 & 0,89 & 0,14 & 0,35 & 1 \\
\hline Пояс 4 & 298 & 0,90 & 0,15 & 0,11 & 1 \\
\hline Пояс 5 & 298 & 0,84 & 0,22 & 0,11 & 1 \\
\hline Пояс 6 & 298 & 0,80 & 0,26 & 0,06 & 1 \\
\hline Пояс 7 & 298 & 0,67 & 0,34 & 0,02 & 1 \\
\hline Пояс 8 & 298 & 0,63 & 0,35 & 0,02 & 1 \\
\hline Пояс 9 & 298 & 0,72 & 0,31 & 0,01 & 1 \\
\hline
\end{tabular}

тому дополнительно были собраны данные о характеристиках постановок. Спектакли были классифицированы по типу постановки (опера / балет), дате написания (классическая / современная), национальной принадлежности автора (русский /иностранный), дате премьеры постановки в театре (премьерный / непремьерный сезон).

Для оценки качества постановки мы имеем информацию о дирижере, среди которых из прочих выделили наиболее популярных дирижеров Пермского театра. Место постановки во всемирном рейтинге также позволит оценить качество спектакля. Для оценки 
качества оперы мы использовали всемирный рейтинг опер и их композиторов (operabase.com). Данный источник ранжирует оперы и композиторов по числу показов в мире, проставляя их места от 1 до 30. Операм и композиторам, которые не представлены в данном рейтинге, но присутствуют в данных, было проставлено место 99. Для оценки качества балетов мы использовали рейтинг другого ресурса (listverse.com), который выбрал и ранжировал десять лучших балетов со всего мира по числу показов. Балеты, не представленные в данном рейтинге, были классифицированы аналогичным операм способом. Далее для объяснения вариации заполняемости зала мы будем использовать такую меру качества постановки, как единицу, деленную на место в рейтинге. Данная мера прямо пропорционально отражает качество постановки, а также учитывает убывающий предельный эффект от роста номера места в рейтинге. С 1998 г. театр регулярно номинируется на российскую национальную театральную премию «Золотая маска» (3М), по каждой постановке имеются данные по числу номинаций и числу выигранных наград, что отражает признание постановок театральным экспертным сообществом. Для каждой постановки мы также собрали информацию о возрасте, начиная с которого театр рекомендует посещать постановку в соответствии с ее содержанием. Описательные статистики по характеристикам постановок представлены в табл. 2 и 3.

Так, примерно две трети всех показов составляют показы опер, одна треть - балеты, большая часть произведений (86\%) классические произведения, которые играются в вечернее время (87\%). Спектакли показываются как в выходные (54\%), так и рабочие дни. Среди авторов показанных произведений часто встречаются как русские авторы (57\%), так и зарубежные. Небольшую долю спектаклей составляют современные постановки (14\%), постановки с жестким ограничением зрительской аудитории по возрасту (15\%), спектакли с номинациями (18\%) и победами (5\%) премии «Золотая маска», а также детские спектакли, которые показывают в утреннее время $(13 \%)$.

Таблица 2

Описательные статистики непрерывных переменных

\begin{tabular}{|c|c|c|c|c|c|c|}
\hline Переменная & Описание & $\begin{array}{c}\text { Число } \\
\text { наблюде- } \\
\text { ний }\end{array}$ & $\begin{array}{l}\text { Среднее } \\
\text { значение }\end{array}$ & $\begin{array}{c}\text { Стандарт- } \\
\text { ное откло- } \\
\text { нение }\end{array}$ & $\begin{array}{c}\text { Мини- } \\
\text { мальное } \\
\text { значение }\end{array}$ & $\begin{array}{c}\text { Макси- } \\
\text { мальное } \\
\text { значение }\end{array}$ \\
\hline $\begin{array}{l}\text { Рейтинг } \\
\text { оперы }\end{array}$ & $\begin{array}{l}1 /(\text { место в рейтинге } \\
\text { опер) }\end{array}$ & 2682 & 0,08 & 0,22 & 0,01 & 1 \\
\hline $\begin{array}{l}\text { Рейтинг } \\
\text { композитора }\end{array}$ & $\begin{array}{l}1 /(\text { место в рейтинге } \\
\text { композиторов опер) }\end{array}$ & 2682 & 0,09 & 0,21 & 0,01 & 1 \\
\hline $\begin{array}{l}\text { Рейтинг } \\
\text { балета }\end{array}$ & $\begin{array}{l}1 / \text { (место в рейтинге } \\
\text { балетов) }\end{array}$ & 2682 & 0,09 & 0,22 & 0,01 & 1 \\
\hline
\end{tabular}


Таблица 3

Описательные статистики фиктивных переменных

\begin{tabular}{|c|c|c|}
\hline Переменная & Число наблюдений & Доля наблюдений, \% \\
\hline Сезоны & 2682 & \\
\hline $2011 / 2012$ & 828 & 30,9 \\
\hline $2012 / 2013$ & 819 & 30,5 \\
\hline $2013 / 2014$ & 711 & 26,5 \\
\hline $2014 / 2015$ & 324 & 12,1 \\
\hline День недели & 2682 & \\
\hline Рабочие дни & 1440 & 46,3 \\
\hline Выходные & 1242 & 53,7 \\
\hline Время дня & 2682 & \\
\hline До 14 & 342 & 12,8 \\
\hline С 14 и позднее & 2340 & 87,2 \\
\hline Тип спектакля & 2682 & \\
\hline Балет & 954 & 35,6 \\
\hline Опера & 1728 & 64,4 \\
\hline Дата создания & 2682 & \\
\hline Ранее 1900 г. & 2304 & 85,9 \\
\hline 1900 г. и позднее & 378 & 14,1 \\
\hline Допустимый возраст & 2682 & \\
\hline От 0 лет & 1107 & 41,3 \\
\hline От 12 лет & 1170 & 43,6 \\
\hline От 16 лет & 405 & 15,1 \\
\hline Дирижер & 2682 & \\
\hline Теодор Курентзис & 279 & 10,4 \\
\hline Валерий Платонов & 1422 & 53,0 \\
\hline Виталий Полонский & 72 & 2,7 \\
\hline Другие & 909 & 33,9 \\
\hline $\begin{array}{l}\text { Наличие номинаций } \\
\text { в «Золотой маске» }\end{array}$ & 2682 & \\
\hline Есть номинации & 486 & 18,1 \\
\hline Нет номинации & 2196 & 91,9 \\
\hline $\begin{array}{l}\text { Наличие побед в «Золотой } \\
\text { маске» }\end{array}$ & 2682 & \\
\hline Есть победы & 144 & 5,4 \\
\hline Нет побед & 2538 & 94,6 \\
\hline Национальность автора & 2682 & \\
\hline Русский & 1521 & 56,7 \\
\hline Другой & 1161 & 43,3 \\
\hline
\end{tabular}




\section{3. Методология}

Как было сказано выше, под единицей наблюдения будем понимать комбинацию показа конкретной постановки и ценового пояса. Мерой спроса будет заполняемость ценового пояса, рассчитанная как отношение числа проданных билетов в ценовой пояс к общему числу мест в поясе. Детерминантами спроса в соответствии с предыдущими исследованиями выступают цена билета в ценовой пояс, характеристики постановки и конкретного ее показа, а также качество ценового пояса. Так, функцию спроса можно записать как

$$
y_{i j k}=F\left(x_{i j}, x_{j}, p_{i j k}, D_{k}, e_{i j k}\right),
$$

где $y_{i j k}-$ спрос на показ $i$ постановки $j$ в ценовой пояс $k ; x_{i j}$-характеристики показа $i$ постановки $j$ (время показа, день недели, месяц, сезон); $x_{j}$ - характеристики постановки $j$ (тип постановки, характеристики произведения, режиссер, дирижер и др.); $p_{i j k}$ - базовая цена билета на показ $i$ постановки $j$ в ценовой пояс $k ; D_{k}$ - дамми-переменная на принадлежность поясу $k$; $e_{i j k}-$ случайная ошибка.

В данной работе мы оценим функцию спроса различными способами.

Во-первых, для сравнения результатов с предыдущими исследованиями оценим параметры функции спроса методом наименьших квадратов для наблюдений, агрегированных до уровня спектакля, где наблюдением является показ спектакля:

$$
E\left[\bar{y}_{i j} \mid x, p\right]=\left(x_{i j}, x_{j}\right) \beta+\gamma \bar{p}_{i j},
$$

где $\bar{y}_{i j .}=\sum_{k=1}^{9} y_{i j k} z_{k} / \sum_{k=1}^{9} z_{k}-$ спрос (доля заполняемости зала) на показ $i$ постановки $j ; z_{k}$ - вместимость пояса $k ; \bar{p}_{i j}=\sum_{k=1}^{9} p_{i j k} z_{k} / \sum_{k=1}^{9} z_{k}-$ средняя цена билета на показ $i$ постановки $j ; \beta$ - вектор параметров влияния характеристик постановки на спрос; $\gamma$ - параметр чувствительности спроса к цене билета.

Во-вторых, оценим параметры функции спроса методом наименьших квадратов для структуры данных, дезагрегированной до уровня ценового пояса, для того чтобы учесть качество мест в зрительном зале:

$$
E\left[y_{i j k} \mid x, p, D\right]=\left(x_{i j}, x_{j}\right) \beta+\gamma p_{i j k}+D_{k} \alpha_{k},
$$

где $\alpha_{k}-$ параметр качества ценового пояса $k$.

Сравнение оценок уравнений (2) и (3) позволяет судить о том, различают ли зрители качество мест в зале, а также является ли цена билета в ценовой пояс сигналом о его качестве. Так, если МНК-оценка ценовой эластичности $\gamma$ на агрегированных данных без контроля качества места является отличной от оценки на дезагрегированных данных, то это позволяет говорить о том, что для зрителей цена билета является сигналом качества. Кроме того, если присутствует положи- 
тельная корреляция между ценой и качеством места, а цена отрицательно влияет на спрос, то оценка $\gamma$ для уравнения (2) будет занижена в абсолютных значениях по сравнению с оценкой в уравнении (3). Это означает, что оценка эластичности модели на агрегированных данных будет ниже, а это согласуется с типичными выводами о том, что спрос на театральные постановки, оцененный на агрегированных данных, менее эластичен по цене.

Далее оценим параметры функции спроса на дезагрегированных данных с помощью модели медианной регрессии. Такой подход позволяет оценить параметры функции спроса для медианного ценового пояса, избавляясь от смещения результатов ввиду наличия аномальных наблюдений, существенно влияющих на среднее значение заполняемости. Данный подход для оценки функции спроса на театральные постановки был впервые использован в работе (Laamanen, 2013), что также позволяет сравнить оценки, полученные в данной работе, с оценками функции спроса на данных финской оперы. Модель функции спроса можно записать в виде:

$$
Q_{y_{i k k} x, p, D}=\left(x_{i j}, x_{j}\right) \beta+\gamma p_{i j k}+D_{k} \alpha_{k},
$$

где $Q_{y_{i j k} \mid x, p, D}-$ условная медиана спроса.

На рис. 2 видно, что больше половины наблюдений заполнены на $80 \%$ и выше. При этом треть ценовых поясов были заполнены полностью. Следует учитывать, что заполняемость пояса не может превышать $100 \%$ и не может быть меньше 0, т.е. она является цензурированной. При ограниченном числе мест в зале и поясе следует различать потенциальный и фактический спрос на услуги театра (Laamanen, 2013). Спрос на спектакли, который мы наблюдаем, является фактическим. При этом потенциальный спрос совпадает с фактическим, если заполняемость зала меньше $100 \%$, т.е. все, кто хотел приобрести билеты на спектакль, сделали это. Если фактический наблюдае-

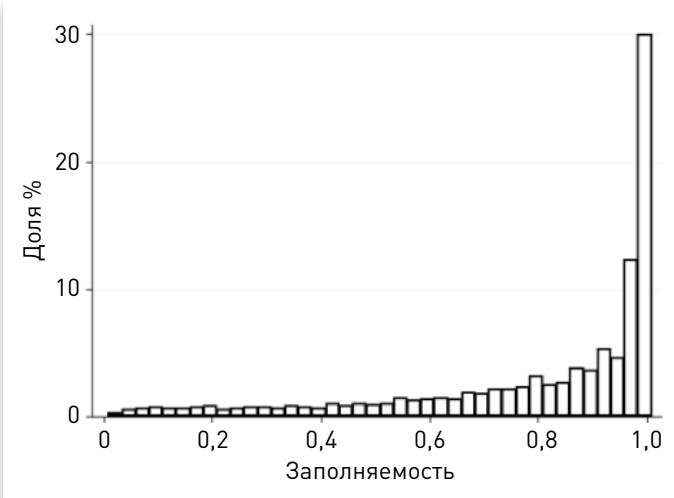

Puc. 2

Гистограмма плотности заполняемости иеновых поясов мый спрос равен $100 \%$, то могли остаться потребители, чей спрос не был удовлетворен. В таких случаях говорят, что потенциальный спрос превышает $100 \%$, а значит, наблюдаемая зависимая переменная не отражает истинного значения спроса. То же верно и для отрицательного потенциального спроса. Поскольку треть наблюдений имеет заполняемость, равную $100 \%$, то в модели необходимо учесть цензурированность зависимой переменной сверх $100 \%$. Неучет цензурирования сверху 
приведет к недооценке абсолютных значений эффектов и смещению оценок параметров. Поскольку всего в данных имеется четыре наблюдения, где заполняемость была равна 0 , что от общей доли наблюдений составляет менее одного процента, то цензурирование зависимой переменной нулем снизу можно не учитывать, поскольку это не приведет к значимому смещению параметров. Таким образом, для оценивания цензурированной сверху функции спроса в данной работе будет использована модель цензурированной медианной регрессии, метод оценивания которой предложен в работе (Chernozhukov, Hong, 2011). Цензурированный характер зависимой переменной также можно учесть с помощью тобит-модели, однако она требует предпосылок о распределении зависимой переменной, чего не требует модель цензурированной медианной регрессии. Функция спроса может быть представлена как:

$$
\begin{gathered}
Q_{y_{i j k}^{*} \mid x, p, D}=\left(x_{i j}, x_{j}\right) \beta+\gamma p_{i j k}+D_{k} \alpha_{k}, \\
Q_{y_{i j k} \mid x, p, D}=\left\{\begin{array}{c}
Q_{y_{i j k}^{*} \mid x, p, D}, Q_{y_{i j k}^{*} \mid x, p, D} \leq 1 ; \\
1, Q_{y_{i j k}^{*} \mid x, p, D}>1,
\end{array}\right.
\end{gathered}
$$

где $Q_{y_{i k j}^{*} \mid x, p, D}-$ условная медиана потенциального спроса; $Q_{y_{j k j} \mid x, p, D}-$ условная медиана фактического спроса; $y^{*}$ - потенциальный спрос, измеряемый в долях единицы; $y$ - фактический спрос, измеряемый в долях единицы.

\section{4. Результаты эконометрического оценивания}

В табл. 4 представлены результаты оценки параметров различных спецификаций функции спроса. Так, из сравнения МНК-оценок для данных, агрегированных до уровня спектакля (2) и до уровня ценового пояса (3) при контроле качественных характеристик спектаклей, видно, что оценка ценовой эластичности на агрегированных данных является заниженной в абсолютных значениях. Это свидетельствует о том, что зрители театра различают места по качеству, предъявляя больший спрос на более дорогие места при прочих равных. Неучет качества места приводит к неверной интерпретации результатов оценки ценовой эластичности, свидетельствуя о неэластичности спроса. Кроме того, пропуск качественных характеристик постановки также будет приводить к увеличению оценки ценовой эластичности. Так, в регрессии (1) зависимости заполняемости только от цены билета оценка ценовой эластичности имеет положительный знак, что говорит о наличии смещения ввиду наличия пропущенной переменной качества. Результаты оценивания спецификаций на агрегированных данных согласуются с результатами ранних исследований по оценке функции спроса на агрегированных данных. Результаты оценки спецификаций (3)-(5) с контролем качества постановок и мест в зале подтверждают гипотезу о том, что спрос является слабо эластичным по цене. 
Кроме того, мы решили проверить оценки параметров на необходимость использовать модели цензурированной медианной регрессии, тестируя на наличие смещения оценок ввиду цензурированной природы спроса. Видно, что оценки әффекта цены различаются при сравнении спецификаций (4) и (5). В спецификации (4) по сравнению с (5) значение эффекта цены меньше по модулю, что объясняется неучетом цензурированного характера зависимой переменной. Значения эффектов остальных переменных в случае медианной регрессии также меньше в абсолютном выражении по сравнению с цензурированной медианной регрессией, что, в конечном счете, требует использовать цензурированную медианную регрессию.

Так, цена является значимым фактором при моделировании спроса на спектакли. Функция посетителей Пермского театра оперы и балета в среднем слабо эластична по цене (эластичность -0,117). Данный результат расходится с оценкой функции спроса на финскую оперу (эластичность $--1,17$ ), что может объясняться более высоким качеством постановок пермского театра и способностью пермской публики распознавать это качество. Отрицательный знак параметра и его значимость означает также, что для зрителей Пермского театра оперы и балета нехарактерен эффект Веблена, т.е. рост потребления товара по мере роста цены.

Помимо прочего, результаты показывают, что произведения, написанные русскими авторами, имеют больший успех у посетителей театра по сравнению с остальными спектаклями. Кроме того, заполняемость поясов на премьерные спектакли в среднем превышает заполняемость поясов на спектакли, демонстрирующиеся не первый год. Также можно заметить, что посетители в среднем больше предпочитают ходить на балеты, чем на оперы, что согласуется с интуитивным представлением о том, что балет является более понятным культурным продуктом, чем опера, которую слушает обычно более подготовленная публика. Данный факт подтверждается также положительным эффектом рейтинга балета, показывающего увеличение посещаемости массовых классических балетов. Среди показателей качества постановки положительный вклад в посещаемость спектаклей привносит число у спектакля наград в «Золотой маске». Также видно, что по сравнению с постановками, посещение которых разрешено людям любого возраста, включая детей, постановки, рекомендованный возраст для просмотра которых начинается с 12 лет, лучше заполняются, что объясняется различием в содержании спектаклей. Постановки, посещение которых разрешено всем без ограничений, - как правило, детские и семейные спектакли.

При этом наиболее популярные спектакли - «взрослые» спектакли, посещение которых рекомендовано после достижения 12 лет, однако постановки, рекомендуемый возраст просмотра которых начинается с 16 лет, в среднем заполняются хуже детских и семейных, что 
Таблица 4

Результаты оценивания функции спроса

\begin{tabular}{|c|c|c|c|c|c|}
\hline \multirow{3}{*}{ Переменная } & \multicolumn{5}{|c|}{ Модель } \\
\hline & (1) & (2) & (3) & (4) & (5) \\
\hline & MHK & MHK & MHK & $\begin{array}{c}\text { Медианная } \\
\text { регрессия }\end{array}$ & $\begin{array}{c}\text { Цензурированная } \\
\text { медианная регрессия }\end{array}$ \\
\hline \multirow{2}{*}{ Логарифм цены } & $0,166^{* * *}$ & $-0,043$ & $-0,097^{* * *}$ & $-0,073^{* * *}$ & $-0,117^{* * *}$ \\
\hline & $(0,017)$ & $(0,025)$ & $(0,012)$ & $(0,019)$ & $(0,024)$ \\
\hline \multirow{2}{*}{ Автор из России } & & $0,054^{* *}$ & $0,057^{* * *}$ & $0,048^{* *}$ & $0,096^{* * *}$ \\
\hline & & $(0,017)$ & $(0,010)$ & $(0,017)$ & $(0,019)$ \\
\hline \multirow{2}{*}{ Премьерный год } & & $0,105^{* * *}$ & $0,106^{* * *}$ & $0,108^{* * *}$ & $0,162^{* * *}$ \\
\hline & & $(0,023)$ & $(0,014)$ & $(0,023)$ & $(0,028)$ \\
\hline \multirow{2}{*}{ Рейтинг оперы } & & 0,066 & 0,048 & $0,121^{* *}$ & 0,029 \\
\hline & & $(0,045)$ & $(0,027)$ & $(0,044)$ & $(0,047)$ \\
\hline \multirow{2}{*}{ Рейтинг балета } & & 0,072 & $0,103^{* * *}$ & 0,073 & $0,228^{* * *}$ \\
\hline & & $(0,038)$ & $(0,023)$ & $(0,037)$ & $(0,057)$ \\
\hline \multirow{2}{*}{ Тип спектакля - балет } & & $0,298^{* * *}$ & $0,326^{* * *}$ & $0,245^{* * *}$ & $0,399^{* * *}$ \\
\hline & & $(0,026)$ & $(0,014)$ & $(0,023)$ & $(0,028)$ \\
\hline \multirow{2}{*}{$\begin{array}{l}\text { Число взятых побед } \\
\text { в «Золотой маске» }\end{array}$} & & 0,033 & $0,039^{* * *}$ & $0,054^{* *}$ & $0,045^{*}$ \\
\hline & & $(0,019)$ & $(0,012)$ & $(0,019)$ & $(0,020)$ \\
\hline \multirow{2}{*}{$\begin{array}{l}\text { Дирижер Валерий } \\
\text { Платонов }\end{array}$} & & $-0,036$ & $-0,040^{* * *}$ & $-0,028$ & $-0,078^{* * *}$ \\
\hline & & $(0,019)$ & $(0,011)$ & $(0,018)$ & $(0,021)$ \\
\hline \multirow{2}{*}{$\begin{array}{l}\text { Дирижер Виталий } \\
\text { Полонский }\end{array}$} & & $0,230^{* * *}$ & $0,258^{* * *}$ & $0,279^{* * *}$ & $0,266^{* * *}$ \\
\hline & & $(0,054)$ & $(0,032)$ & $(0,052)$ & $(0,057)$ \\
\hline \multirow{2}{*}{$\begin{array}{l}\text { Дирижер Теодор } \\
\text { Курентзис }\end{array}$} & & 0,019 & 0,028 & $-0,001$ & 0,062 \\
\hline & & $(0,032)$ & $(0,019)$ & $(0,031)$ & $(0,035)$ \\
\hline \multirow{2}{*}{$\begin{array}{l}\text { Допустимый возраст: } \\
\text { с } 12 \text { лет }\end{array}$} & & 0,018 & $0,033^{* *}$ & 0,006 & $0,040^{*}$ \\
\hline & & $(0,018)$ & $(0,011)$ & $(0,018)$ & $(0,020)$ \\
\hline \multirow{2}{*}{$\begin{array}{l}\text { Допустимый возраст: } \\
\text { с } 16 \text { лет }\end{array}$} & & $-0,076^{*}$ & $-0,077^{* * *}$ & $-0,151^{* * *}$ & $-0,105^{* * *}$ \\
\hline & & $(0,030)$ & $(0,018)$ & $(0,030)$ & $(0,031)$ \\
\hline \multirow{2}{*}{$\begin{array}{l}\text { Время дня: с } 14 \\
\text { и позднее }\end{array}$} & & $-0,022$ & $-0,025$ & $-0,004$ & $-0,018$ \\
\hline & & $(0,023)$ & $(0,014)$ & $(0,022)$ & $(0,026)$ \\
\hline \multirow{2}{*}{ Константа } & $0,616^{* * * *}$ & $0,635^{* * *}$ & $1,247^{* * *}$ & $1,170^{* * *}$ & $1,371^{* * *}$ \\
\hline & $(0,021)$ & $(0,035)$ & $(0,071)$ & $(0,115)$ & $(0,142)$ \\
\hline$N$ & 298 & 298 & 2682 & 2682 & 2682 \\
\hline$k$ & 2 & 27 & 35 & 35 & 35 \\
\hline$R^{2}$ & 0,250 & 0,665 & 0,467 & & \\
\hline
\end{tabular}

Примечание. В ячейках таблицы представлены оценки параметров, в скобках стандартные ошибки. Символами «"», «**», «***» обозначены оценки, значимые на уровне 5,1 и 0,1\% соответственно; $N-$ число наблюдений, $k$ - число параметров. В моделях (1)-(2) уровень агрегирования - спектакли, в (3)-(5) ценовые пояса спектаклей. В моделях (2)-(5) также учтены в качестве контрольных фиктивные переменные: сезон, месяц. В (3)-(5) - ценовой пояс. Базовые категории: тип спектакля - опера, дирижеры - другие дирижеры, допустимый возраст - с 0 лет, время дня - до 14 часов. 
происходит из-за сильного сужения круга потенциальных посетителей и специфического содержания. В моделях (2)-(5) учтена сезонность путем включения дамми-переменных на отдельные месяцы и влияние внешнего окружения включением дамми-переменных на отдельные сезоны. Так, спрос на театральные постановки подвержен внутригодовой сезонности с пиком посещаемости в середине театрального сезона (декабрь, февраль, март). Наиболее слабо заполняются залы в конце и начале сезона (сентябрь, май, июнь). Контроль на наличие тренда в посещаемости по сезонам показывает, что спрос неизменно растет по сезонам. Вероятно, это связано с началом работы нового художественного руководителя театра в сезоне 2011/2012 и привыканием публики к новому формату постановок. Различные внешние по отношению к театру переменные (ИПЦ на кино, театры и концерты, реальные доходы населения) не объясняют дополнительной вариации в спросе по сезонам.

\section{Заключение}

Исследования, посвященные рынку театральных услуг, затрагивают различные вопросы, начиная с ценовой дискриминации в театре, заканчивая выявлением портрета типичного посетителя театра. Среди них лишь небольшая доля работ посвящена эмпирическим исследованиям функции спроса на театральные постановки. Обзор литературы показывает, что идентификация функции спроса может осуществляться на разных по структуре данных. Ранние исследования в основном проводились на агрегированных данных: в целом по театру или по отдельным сценам, - что приводило к весьма различным оценкам ценовой эластичности спроса. В современных работах авторы используют дезагрегированные данные до уровня отдельных сегментов, спектаклей, однако оценивание функции спроса для ценовых поясов впредь еще не осуществлялось. Данные, предоставленные для исследования Пермским театром оперы и балета, позволили сформировать структуру данных таким образом, чтобы оценить спрос не для зала в целом, а для конкретного ценового пояса. Поскольку места в зале имеют разное удаление от сцены и также различаются по цене, то заполняемость зала также может различаться для разных мест в зале. Оценка функции спроса в разрезе ценовых поясов позволила оценить качество отдельного пояса и избавиться от смещения оценок параметров функции спроса.

Результаты оценивания цензурированной квантильной регрессии показали, что спрос является эластичным по цене с отрицательным знаком, что опровергает гипотезу об эффекте Веблена. Кроме того, мы выявили, что спрос на театральные услуги Пермского театра оперы и балета является слабо эластичным по цене. Это может объясняться как отсутствием близких субститутов, так как театр является единственным музыкальным театром в Перми, так и тем, что театр 
стремится удерживать высокое качество постановок, а пермские зрители славятся своей искушенностью и образованностью в театральном искусстве. Кроме цены, на посещаемость зрителей театров влияет национальность автора - зрители предпочитают посещать постановки российских авторов. Также люди охотнее идут на премьерные показы спектаклей. В целом зрители больше любят балеты, чем оперы, среди которых предпочтение отдают всемирно известным постановкам: «Лебединое озеро», «Жизель», «Дон Кихот» и «Ромео и Джульетта». Также посетители обращают внимание на дирижеров постановок, среди которых у них есть свои фавориты.

Оценка функции спроса также позволяет выработать рекомендации относительно эффективного ценообразования. Так, около трети всех ценовых поясов на ретроспективных данных являются заполненными полностью, это означает, что потенциальный спрос в эти ценовые пояса спектаклей превышает вместимость зала. Данный факт позволяет говорить о том, что увеличение цены билетов для этих наблюдений могло бы привести к повышению выручки от продажи билетов без снижения фактической заполняемости зала. Среди таких постановок можно отметить балеты (в $60 \%$ случаев заполняются полностью), классические балеты с мировым рейтингом (в $65 \%$ случаев заполняются полностью), места в центре зала, а именно - со второго по шестой ряд, на показы балетов (в 62-82\% случаев заполняются полностью), балеты русских композиторов (в $72 \%$ случаев заполняются полностью). Таким образом, ввиду того что балеты в театре идут реже, чем оперы, а также того факта, что классический русский балет является визитной карточкой Пермского театра оперы и балета (театр, который горячо любит публика), рекомендацией, направленной на увеличение выручки, было бы увеличение частоты показов балета или установление более высоких цен на удобные места в центре зала именно на показы классического балета.

Описывая результаты, стоит упомянуть ограничения работы. Изначально, формируя структуру данных, мы упоминали о том, что места в зале разнородны по расположению, удаленности от сцены, соответственно по качеству обзора сцены, качеству звука и, конечно, цене. Ограничиваясь оценкой спроса для отдельных ценовых зон, мы пренебрегаем разнородностью мест, находящихся в одном ценовом поясе, предполагая, что места внутри одного пояса однородны. Оценка спроса на каждое место в зале позволило бы избежать этой проблемы, однако это привело бы к значительным вычислительным трудностям. Кроме того, ввиду отсутствия социально-демографической информации о покупателях билетов данное исследование не позволяет выявить эффект дохода и образования на спрос отдельных индивидов. Таким образом, исследование разнородности предпочтений потребителей также остается за рамками данного исследования. 
В описании данных также упоминалось, что мы имеем информацию как о базовой цене продажи билета, которая и была использована в качестве меры цены, так и о фактической цене продажи билета с учетом скидки. Театр имеет систему предоставления скидок. Используя базовую цену продажи в качестве меры цены, мы не учитываем скидок, предоставляемых потребителям, что, несомненно, является важным допущением, поскольку скидка является дополнительным стимулом для тех категорий, которым она предоставляется. Поскольку целью данного исследования также является предоставление рекомендаций театру, то использование базовой цены представляется наиболее релевантным инструментом, так как театр может управлять именно базовой ценой.

Наконец, потребители, выбирая билет на спектакль, могут переключаться между разными ценовыми зонами. Соответственно, покупая билет, они опираются также и на заполняемость соседних ценовых зон, где качество обзора и вида, а также цена, несильно различаются по сравнению с рассматриваемым поясом. На данный момент, оценивая спрос, мы не учитываем заполняемость других поясов. Поэтому в качестве направления дальнейшего исследования стоит выделить оценку системы одновременных уравнений, где будет оцениваться заполняемость каждого пояса, при этом заполняемость одного пояса будет зависеть от заполняемости всех остальных мест в зале.

\section{ЛИТЕРАТУРА}

Автономов Ю.В. (2011). Эмпирические исследования спроса на культурные блага: исполнительское искусство и объекты культурного наследия. М.: Институт экономики РАН.

Автономов Ю.В. (2014). Эластичность спроса на исполнительское искусство по цене и доходу: основные результаты эмпирических исследований // Measurement Techniques. Vol. 56 (12). P. 1323-1326.

Рубинштейн А.Я. (2012). Опекаемые блага в сфере культуры: признаки и последствия «болезни цен». М.: ИЭ РАН.

Baumol W.J., Bowen W.G. (1966). Performing Arts - the Economic Dilemma: A Study of Problems Common to Theatre, Opera, Music and Dance. Cambridge: MIT Press.

Bonato L., Gagliardi F., Gorelli S. (1990). The Demand for Live Performing Arts in Italy / / Journal of Cultural Economics. Vol. 14 (2). P. 41-52.

Borland J., MacDonald R. (2003). Demand for Sport. Oxford Review of Economic Policy. Vol. 19 (4). P. 478-502.

Chernozhukov V., Hong H. (2011). Three-Step Censored Quantile Regression and Extramarital Affairs // Journal of the American Statistical Association. Vol. 97. No. 459. P. 872-882.

Choi C., Jeong M., Mattila A.S. (2015). Revenue Management in the Context of Movie Theaters: Is It Fair? / / Journal of Revenue and Pricing Management. Vol. 14 (2). P. 72-83. 
Colbert F., Nantel J. (1989). The Market for Cultural Activities: New Approaches for Segmentation Studies. In: Chartrand H.H., Hendon W.S., McCaughey C. (eds) "Cultural Economics '88: A Canadian Perspective”. Akron: ACEI. P. 133-140.

Corning J., Levy A. (2002). Demand for Live Theater with Market Segmentation and Seasonality / / Journal of Cultural Economics. Vol. 26 (3). P. 217-235.

Felton M.V. (1989). Major Influences on the Demand for Opera Tickets / / Journal of Cultural Economics. Vol. 13 (1). P. 53-64.

Gapinski J.H. (1984). The Economics of Performing Shakespeare // The American Economic Review. Vol. 74 (3). P. 458-466.

Greckel F.R., Felton M.V. (1987). Price and Income Elasticities of Demand: A Case Study of Louisville / / In: Grant N.K. et al. (eds) "Economic Efficiency and the Performing Arts”. Akron: ACEI. P. 62-73.

Hansmann H. (1981). Nonprofit Enterprise in the Performing Arts // The Bell Journal of Economics. Vol. 12. No. 2. P. 341-361.

Houthakker H.S., Taylor L.D. (1970). Consumer Demand in the United States. Cambridge: Harvard University Press.

Jenkins S., Austen-Smith D. (1987). Interdependent Decision-Making in Non-Profit Industries: A Simultaneous Equation Analysis of English Provincial Theatre // International Journal of Industrial Organization. Vol. 5 (2). P. 149-174.

Kimes S.E., Chase R.B. (1998). The Strategic Levers of Yield Management / / Journal of Service Research. Vol. 1 (2). P. 156-166.

Kimes S.E., Wirtz J. (2003). Has Revenue Management become Acceptable? Findings from an International Study on the Perceived Fairness of Rate Fences // Journal of Service Research. Vol. 6 (2). P. 125-135.

Krebs S., Pommerehne W. (1995). Politico-Economic Interactions of German Public Performing Arts Institutions / / Journal of Cultural Economics. Vol. 19 (1). P. 17-32.

Laamanen J.P. (2013). Estimating Demand for Opera Using Sales System Data: The Case of Finnish National Opera / / Journal of Cultural Economics. Vol. 37 (4). P. 417-432.

Levy-Garboua L., Montmarquette C. (1996). A Microeconometric Study of Theatre Demand // Journal of Cultural Economics. Vol. 20 (1). P. 25-50.

Litman B.R. (1998). The Motion Picture Mega-Industry. Boston: Allyn \& Bacon.

Moore T.G. (1966). The Demand for Broadway Theater Tickets / / Review of Economics and Statistics. Vol. 48 (1). P. 79-87.

Orbach B.Y., Einav L. (2007). Uniform Prices for Differentiated Goods: The Case of the Movie-Theater Industry / / International Review of Law and Economics. Vol. 27 (2). P. 129-153.

Pommerehne W., Kirchgassner G. (1987). The Impact of Television on the Demand for Cinema and Theatre Performances. In: Grant N.K. et al. (eds) "Economic Efficiency and the Performing Arts". Akron: ACEI. P. 44-61.

Schimmelpfennig J. (1997). Demand for Ballet: a Non-Parametric Analysis of the 1995 Royal Ballet Summer Season / / Journal of Cultural Economics. Vol. 21 (2). P. 119-127.

Schulze G., Rose A. (1998). Public Orchestra Funding in Germany - an Empirical Investigation // Journal of Cultural Economics. Vol. 22 (4). P. 227-247. 
Seaman B.A. (2006). Empirical Studies of Demand for the Performing Arts. In: Ginsburgh V., Throsby D. (eds) "Handbook of the Economics of Arts and Culture" (Chap. 14). NorthHolland: Elsevier. P. 415-472.

Throsby D. (1990). Perception of Quality in Demand for the Theatre // Journal of Cultural Economics. Vol. 14 (1). P. 65-82.

Throsby D. (1994). The Production and Consumption of the Arts: A View of Cultural Economics / / Journal of Economic Literature. Vol. 32 (1). P. 1-29.

Throsby D., Withers G.A. (1979). The Economics of the Performing Arts. New-York: St. Martins.

Touchstone S.K. (1980). The Effects of Contributions on Price and Attendance in the Lively Arts / / Journal of Cultural Economics. Vol. 4 (1). P. 33-46.

Urrutiaguer D. (2002). Quality Judgements and Demand for French Public Theatre / / Journal of Cultural Economics. Vol. 26 (3). P. 185-202.

Willis K., Snowball J. (2009). Investigating How the Attributes of Live Theatre Productions Influence Consumption Choices Using Conjoint Analysis: The Example of the National Arts Festival, South Africa / / Journal of Cultural Economics. Vol. 33 (3). P. 167-183.

Withers G. (1980). Unbalanced Growth and the Demand for the Performing Arts: An Econometric Analysis / / Southern Economic Journal. Vol. 46. P. 735-742.

Zieba M. (2009). Full-Income and Price Elasticities of Demand for German Public Theatre / / Journal of Cultural Economics. Vol. 33 (2). P. 85-108.

Поступила в редакиию 28 сентября 2017 года

\section{REFERENCES (with English translation or transliteration)}

Avtonomov Y.V. (2011). Empirical Research of Demand for Cultural Goods: Performing Arts and Cultural Heritage. Moscow: RAS Institute of Economics (in Russian).

Avtonomov Y.V. (2014). Price and Income Elasticity of Demand for Performing Arts: Main Results of Empirical Research. Measurement Techniques, 56 (12), 13231326 (in Russian).

Baumol W.J., Bowen W.G. (1966). Performing Arts - the Economic Dilemma: A Study of Problems Common to Theatre, Opera, Music and Dance. Cambridge: MIT Press.

Bonato L., Gagliardi F., Gorelli S. (1990). The Demand for Live Performing Arts in Italy. Journal of Cultural Economics, 14 (2), 41-52.

Borland J., MacDonald R. (2003). Demand for Sport. Oxford Review of Economic Policy, 19 (4), 478-502.

Chernozhukov V., Hong H. (2011). Three-Step Censored Quantile Regression and Extramarital Affairs. Journal of the American Statistical Association, 97, 459, 872-882.

Choi C., Jeong M., Mattila A.S. (2015). Revenue Management in the Context of Movie Theaters: Is It Fair? Journal of Revenue and Pricing Management, 14 (2), $72-83$. 
Colbert F., Nantel J. (1989). The Market for Cultural Activities: New Approaches for Segmentation Studies. In: Chartrand H.H., Hendon W.S., McCaughey C. (eds) "Cultural Economics '88: A Canadian Perspective”. Akron: ACEI, 133-140.

Corning J., Levy A. (2002). Demand for Live Theater with Market Segmentation and Seasonality. Journal of Cultural Economics, 26 (3), 217-235.

Felton M.V. (1989). Major Influences on the Demand for Opera Tickets. Journal of Cultural Economics, 13 (1), 53-64.

Gapinski J.H. (1984). The Economics of Performing Shakespeare. The American Economic Review, 74 (3), 458-466.

Greckel F.R., Felton M.V. (1987). Price and Income Elasticities of Demand: A Case Study of Louisville. In: Grant N.K. et al. (eds) "Economic Efficiency and the Performing Arts". Akron: ACEI, 62-73.

Hansmann H. (1981). Nonprofit Enterprise in the Performing Arts. The Bell Journal of Economics, 12, 2, 341-361.

Houthakker H.S., Taylor L.D. (1970). Consumer Demand in the United States. Cambridge: Harvard University Press.

Jenkins S., Austen-Smith D. (1987). Interdependent Decision-Making in Non-Profit Industries: A Simultaneous Equation Analysis of English Provincial Theatre. International Journal of Industrial Organization, 5 (2), 149-174.

Kimes S.E., Chase R.B. (1998). The Strategic Levers of Yield Management. Journal of Service Research, 1 (2), 156-166.

Kimes S.E., Wirtz J. (2003). Has Revenue Management become Acceptable? Findings from an International Study on the Perceived Fairness of Rate Fences. Journal of Service Research, 6 (2), 125-135.

Krebs S., Pommerehne W. (1995). Politico-Economic Interactions of German Public Performing Arts Institutions. Journal of Cultural Economics, 19 (1), 17-32.

Laamanen J.P. (2013). Estimating Demand for Opera Using Sales System Data: The Case of Finnish National Opera. Journal of Cultural Economics, 37 (4), 417-432.

Levy-Garboua L., Montmarquette C. (1996). A Microeconometric Study of Theatre Demand. Journal of Cultural Economics, 20 (1), 25-50.

Litman B.R. (1998). The Motion Picture Mega-Industry. Boston: Allyn \& Bacon.

Moore T.G. (1966). The Demand for Broadway Theater Tickets. Review of Economics and Statistics, 48 (1), 79-87.

Orbach B.Y., Einav L. (2007). Uniform Prices for Differentiated Goods: The Case of the Movie-Theater Industry. International Review of Law and Economics, 27 (2), $129-153$.

Pommerehne W., Kirchgassner G. (1987). The Impact of Television on the Demand for Cinema and Theatre Performances. In: Grant N.K. et al. (eds) "Economic Efficiency and the Performing Arts". Akron: ACEI. P. 44-61.

Rubinstein A.Y. (2012). Patronized Goods in the Sphere of Culture: "Price Desease" Features and Effects. Moscow: RAS Institute of Economics (in Russian).

Schimmelpfennig J. (1997). Demand for Ballet: a Non-Parametric Analysis of the 1995 Royal Ballet Summer Season. Journal of Cultural Economics, 21 (2), $119-127$. 
Schulze G., Rose A. (1998). Public Orchestra Funding in Germany - an Empirical Investigation. Journal of Cultural Economics, 22 (4), 227-247.

Seaman B.A. (2006). Empirical Studies of Demand for the Performing Arts. In: Ginsburgh V., Throsby D. (eds) "Handbook of the Economics of Arts and Culture" (Chap. 14). NorthHolland: Elsevier, 415-472.

Throsby D. (1990). Perception of Quality in Demand for the Theatre. Journal of Cultural Economics, 14 (1), 65-82.

Throsby D. (1994). The Production and Consumption of the Arts: A View of Cultural Economics. Journal of Economic Literature, 32 (1), 1-29.

Throsby D., Withers G.A. (1979). The Economics of the Performing Arts. New-York: St. Martins.

Touchstone S.K. (1980). The Effects of Contributions on Price and Attendance in the Lively Arts. Journal of Cultural Economics, 4 (1), 33-46.

Urrutiaguer D. (2002). Quality Judgements and Demand for French Public Theatre. Journal of Cultural Economics, 26 (3), 185-202.

Willis K., Snowball J. (2009). Investigating How the Attributes of Live Theatre Productions Influence Consumption Choices Using Conjoint Analysis: The Example of the National Arts Festival, South Africa. Journal of Cultural Economics, 33 (3), 167-183.

Withers G. (1980). Unbalanced Growth and the Demand for the Performing Arts: An Econometric Analysis. Southern Economic Journal, 46, 735-742.

Zieba M. (2009). Full-Income and Price Elasticities of Demand for German Public Theatre. Journal of Cultural Economics, 33 (2), 85-108.

Received 28.09.2017

\section{A.R. Ozhegova}

National Research University Higher School of Economics, Perm, Russia

E.M. Ozhegov

National Research University Higher School of Economics, Perm, Russia

\section{Estimation of Demand Function for Performing Arts: Empirical Analysis}

Abstract. Government-subsidized theatres in Russia aim to increase both revenue and number of tickets sold. Achievement of such a goal is closely connected with study of theatre tickets demand function focusing on the estimation of price elasticity of demand. Previous papers studied price elasticity of demand for theatrical performances provide controversial results. Estimates of price elasticity varies with countries, theatres, segments of theatre audience and even with level of data aggregation. Ticket sales and price data aggregation at the national level or theatre level typically does not allow to control for the differences in produced cultural goods quality. Incorrect control or ignoring of a theatre, performances and seats quality leads to a problem of omitted variables and bias in price elasticity estimates. In this paper we employ disaggregated ticket sales data for four seasons of Perm opera and ballet theatre and estimate the price effect on the theatrical demand for various performance types and seats in the hall. We use censored quantile regression to estimate the parameters of theatre demand function. We reveal the weak elasticity of demand for Perm opera and ballet theatre. We also show that ignoring the limited capacity of the theatre hall, characteristics of performances and seats quality leads to biased estimates of demand function parameters.

Keywords: demand, theatre, cultural economics, price elasticity.

JEL Classification: Z11, D12, C24. 